\title{
An Interdisciplinary Challenge: Method Triangulation in the Field of Brain Development and Motivation
}

\author{
Diana Raufelder, Danilo Jagenow, \\ Frances Hoferichter \\ Freie Universität, Berlin, Germany
}

\author{
R. Poppy Wilkinson \\ Concordia University, \\ Montréal, Canada
}

\begin{abstract}
An investigation of the development of adolescents' motivation and achievement in school demonstrates how psychology and neuroscience can profit from each other in an empirical and therefore epistemological way through method triangulation. Based on a method triangulative technique that directly links quantitative, experimental, and qualitative data (Treumann, 2005), an interdisciplinary longitudinal (two measure points) study was designed to bridge the gap between neuroscience and psychology in the field of brain development and motivation in adolescence. By using this triangulative technique, the authors minimize the weaknesses of each method and maximize their strengths by combining disparate but complementary approaches. Future implications and challenges of method triangulation in the field of psychology research are discussed.
\end{abstract}

Keywords: method triangulation, motivation, brain development, adolescence, neuroscience

Many research topics straddle two or more disciplines. In the past, the scientific community tended to support the independence of each discipline, illustrated by the increasing number of discipline-specific methods and foci. Today, however, there is an international trend in science towards an interdisciplinary approach. The advent of neuroscience subdisciplines in the field of learning and motivation, such as neuroeducation, social neuroscience, and cultural neurosciences, have enabled novel discoveries to concern the universality and diversity in the dynamic interplay of genes, brain, and behavior. Although the formal study of these subdisciplines has only recently emerged in the past decade, the question of how environment (culture) and biology mutually constitute each other has long been a source of philosophical and scientific curiosity, dating as far back as the 7th century (Chiao, 2010). However, the theoretical and empirical tools necessary to make progress in addressing these outstanding questions have only recently become available. One methodological technique that provides opportunity to cross disciplinary boundaries in an empirical way is method triangulation.

\section{Method Triangulation—Bridging the Gap}

Method triangulation is often used synonymously with the term "mixed methods", because they both denote the merging of different methodological traditions and practices. Method triangulation stresses the direct

Diana Raufelder, Ph.D., Department of Educational Science and Psychology, Freie Universität.

Danilo Jagenow, Ph.D. candidate, Department of Educational Science and Psychology, Freie Universität.

Frances Hoferichter, Ph.D. candidate, Department of Educational Science and Psychology, Freie Universität.

R. Poppy Wilkinson, M.A. candidate, Interpersonal Relationships and Development Laboratory, Centre for Research in Human Development, Concordia University. 
interconnection and interlinkage of data, and mixed methods often employ different methods which are used successively without interconnection and interlinkage. However, many researchers often write interchangeably about "integrating", "combining", and "mixing" methods, sometimes eliding these descriptors with "triangulation", which itself encompasses several meanings. Moran-Ellis et al. (2006) argued that, "Such an elision is problematic since it obscures the difference between: (1) the processes by which methods (or data) are brought into relationship with each other (combined, integrated, and mixed); and (2) the claims made for the epistemological status of the resulting knowledge" (p. 45f).

Originally, the term "triangulation" derived from the sciences of land surveying and navigation: using observations from two additional points to determine the position of a third point (Sharp, 1943). Accordingly, the concept of triangulation in social science research "refers to a process by which a researcher wants to verify a finding by showing that independent measures of it agree with or, at least, do not contradict it" (Miles \& Huberman, 1994, p. 266). Triangulation addresses the richness and complexity of behavior by examining a certain issue from more than one viewpoint. Cohen, Manion, and Morrison (2000) defined triangulation as "the use of two or more methods of data collection in the study of some aspect of human behavior" (p. 233). They distinguished six types of triangulation. Here, the authors focus on the first type "method triangulation", because it combines experimental and nonexperimental methods: neuroscience tests (fMRI (functional magnetic resonance imaging)) and quantitative as well as qualitative methods. The epistemological goal of triangulation is to know more about a phenomenon by bringing together data generated by two or more methods (Moran-Ellis et al., 2006).

The idea of using more than one method to understand a phenomenon has a long history (Erzberger \& Prein, 1997). The nature of human behavior is necessarily complex due to the multitude of internal and external influences. If we want to understand human behavior, for example, adolescents' motivation in its complexity, it behooves us to use different methods when considering internal (i.e., personality and brain) processes as opposed to external processes (i.e., interaction with peers, teachers, and grades), both of which are essential to understand motivation. Following this, method triangulation involves using various complementary, symmetrical, or parallel steps to observe and study a phenomenon (LeBlanc, 1995). Such a multifaceted approach would afford several different views of a phenomenon in order to understand it in its complexity. Furthermore, quantitative, experimental, and qualitative studies have different strength and foci, and implicitly they complement each other and as such enhance the validity of the research findings. The description of triangulative research designs provided in the next paragraph shows that the interlinking of different methods is an important way in bringing different disciplines and different forms of epistemology together.

Most studies that conceptualize methodological triangulation, often (mis)understand method triangulation as studying a phenomenon using different methods independently, instead of validating the findings in a method linking process (Bailey \& Hutter, 2008). Treumann, a German researcher, developed a method triangulative technique that directly links quantitative, experimental, and qualitative data (Treuman, 2005). In the first step, quantitative surveys are conducted to get standardized information about different variables. By using cluster analysis, latent class analysis, or latent profile analysis, different types/profiles of cases can be determined. In the second step, type specific cases from each cluster, class, or profile can be selected chosen out for experimental testing (i.e., neuroscientific tests and psychological tests) to specify the results and each type/class/profile. In the third step, qualitative interviews or participant observation can be used to grasp the participants' point of view, perception, and experience. This final step is also important to specify the classes, 
types, or profiles identified in the previous steps. Often, different sub-types can be figured out by the qualitative methods (the third step). This method triangulative technique is not merely a mathematical combination of methods, rather its focus lies on the interconnection and reciprocity of the results and their interpretation (Popp, 2002).

Using method triangulation promotes a rapprochement between the three rivals, so goals of empirical social research (McGarth, Martin, Kulka, \& Richard, 1982) can all be reached (Treumann, 2005):

(1) By using standardized questionnaires, findings about certain variables (i.e., personal attitudes and behavior) can be assessed;

(2) Experimental neuroscience testing should maximize the validity and precision of these variables;

(3) Qualitative instruments focus on a realistic representation of the participants' point of view, perception, and experience.

The following passages present and illustrate this three-step method triangulative technique that the authors employed in the interdisciplinary study SELF (socio-emotional learning factors) to investigate the development of adolescents' motivation and achievement in school.

\section{Adolescents’ Motivation}

It has come to light that a student's emotions are exceedingly relevant to matters of the mind. As Goleman (2004) said,

Most of us have assumed that the kind of academic learning that goes on in school has little or nothing to do with one's emotions or social environment. Now neuroscience is telling us exactly the opposite. The emotional centers of the brain are intricately interwoven with the neocortical areas involved in cognitive learning. When a child trying to learn is caught up in a distressing emotion, the centers for learning are temporarily hampered. The child's attention becomes preoccupied with whatever may be the source of the trouble ... In short, there is a direct link between emotions and learning. (p. 7f)

With these neuroscientific understanding about learning and motivation, the meaning of social and emotional factors in the school context is being re-examined within the field of educational and developmental psychology. Decades before neuroscientists turned their interest towards learning and motivation, psychological researchers have shown that motivation is related to various outcomes, such as curiosity, learning, persistence, and performance (e.g., Deci \& Ryan, 1985) of utmost importance for school and educational psychology. Based on the initial work of McClelland, Atkinson, Clark, and Lowell (1953), an ever-developing body of research on human motivation has revealed edits multi-dimensional character as a product of interdependence between and amongst many variables (Weiner, 1990; Waugh, 2002). Different models and approaches (i.e., needs model, arousal and anxiety model, achievement and social goal model, and attribution theory) (Waugh, 2002) were developed during the last decades, each focusing on specific dimensions of motivation. But there are no approaches or models, which grasp the complexity of motivation in its entirety (Leo \& Galloway, 1996). Furthermore, the research in motivation has yielded no consistent understanding about the nature or relevance of the construct (Leo \& Galloway, 1996). Nevertheless, if we outline underlying common topics of the different approaches and models, which are directly linked to motivation, three areas of research can be identified: personal development, academic achievement, and social relationships.

Within the school context, personal development, academic achievement, and social relationships and motivation are interwoven aspects of students' daily life. School is not only the environment in which students 
experience academic achievement, it is also a place of personal development where they spend a significant portion of time during their childhood and adolescence. Accordingly, the classroom setting functions not only as an educational arena, but also as a powerful social learning context (Harter, 1996). Based on the increasingly complex nature of social relationships during adolescence, both the student-student relationship and the teacher-student relationship become essential for personal development (Erikson, 1959), as well as for motivation (Wentzel, Battle, Russell, \& Looney, 2010; Wentzel, 2005; Harter, 1996), and academic achievement (Flanagan, Erath, \& Bierman, 2008; Raufelder \& Mohr, 2011; Wentzel, 1998).

\section{Different Motivation Patterns During Adolescence}

The level of children's motivation changes throughout adolescence. Many children's academic motivation decreases over the school years due to changes both in themselves and the school environments they experience (Wigfield \& Eccles, 2001; Eccles \& Midgley, 1990; Wigfield, Eccles, \& Rodriguez, 1998; Stipek, 1996). Such changes lead "some" students to withdraw from achievement situations and avoid such experiences whenever possible (Wigfield \& Eccles, 2001). However, these changes are not necessarily problematic for "other" students (Wigfield \& Eccles, 2001). Indeed, motivation research has revealed the "phenomenon" that some students' school achievement remains constant across their years in school (Deci \& Ryan, 2000); that is, independent of changes in themselves or in the social environment, such students show constant school achievement, and therefore, quite a constant motivation to learn which is independent of the teachers who instruct them and the classmates who surround them. These divergent findings suggest that individual differences in motivation as well as the influence of peers and teachers both play a role in students' motivation and achievement. If we want to understand these differences in motivation patterns through adolescence in its entirety, brain development must be considered as well. Indeed, adolescent neurodevelopment occurs in brain regions associated with motivation, impulsivity, and addiction (Chambers, Taylor, \& Potenza, 2003).

\section{Neuroscience and Motivation}

From a neuroscientist's point of view, motivation can be conceptualized as brain activity that processes "input" information about the internal state of the individual and external environment, which then determines behavioral "output" (Dorman \& Gaudiano, 1998). But instead of a simple reflex system producing discrete behaviors in response to discrete stimuli, motivation must be understood as a higher-order processing designed to organize behavior to maximize survival (Chambers et al., 2003). Considering this complexity, multiple survival goals may be simultaneously important but independently attainable in space and time, and there may exist large numbers of potentially successful behavioral strategies to attain one or more of these goals (Chambers et al., 2003). This variety in potentially successful strategies may also explain the abovementioned differences in motivation patterns during adolescence, such as students differ in deciding for the right strategy.

Adolescence is a time characterized by change hormonally, physically, and mentally. Unlike the sensory and motor cortexes, the frontal cortex continues to be myelinated well into adolescence (Blakemore \& Frith, 2005). These maturational changes in the frontal cortical and subcortical monoaminergic systems partly explain adolescent impulsivity and/or novelty seeking as a transitional trait behavior. Increasingly, adolescents acquire adult-like cognitive and emotional styles (Yates, 1996) and become motivated by adult environmental stimuli (Moore \& Rosenthal, 1992). These developmental neuronal processes may be advantageous in the adolescents' transition to adult (Chambers et al., 2003), but may also contribute to a 
greater decrease in scholastic motivation and an increase in impulsivity. According to Blakemore and Frith (2005), it is possible that the excess of synapses at puberty, which have not yet been incorporated into specialized and functional systems, results in poor, if temporary and cognitive performance. Only later, after puberty, are the excess synapses pruned into specialized and efficient networks. Because the environment affects the brain's synapses during development (Greenough, Black, \& Wallace, 1987), and students' relationships with teachers and peers in school context become essential. Teachers act as adult role models for students and provide non-parental and adult support (Harter, 1996; Wentzel, 2009b). In addition, students' learning process in school is the product of a complex dynamic of educational practices (e.g., teaching styles), as well as student (Hodis, Meyer, McClure, Weir, \& Walkey, 2011) and teacher characteristics, including multiple social, cognitive, and emotional variables (Nickel, 1981). Importantly, teachers do not only convey approval or disapproval for scholastic motivation and achievement, they also communicate their general approval or disapproval for the child as a person (e.g., Harter, 1996; Birch \& Ladd, 1996; Wentzel, 2009b, 1996). Peers, on the other hand, serve as potential companions and friends and as such fulfill important social needs of the developing child (Harter, 1996; Rubin, Bukowski, \& Laursen, 2009; Rubin, Bukowski, \& Parker, 2006). The motivational orientation of the peer group influences individual changes in motivation through the school year (Kindermann, 1993). In addition, students who have troubled relationships with their peers (e.g., peer rejection) later show poor school performance and truancy (i.e., Ollendick, Weist, Borden, \& Greene, 1992; Coie, Lochman, Terry, \& Hyman, 1992; DeRosier, Kupersmidt, \& Patterson, 1994). Wide-ranging positive and negative effects from peers and teachers on academic performance and one's sense of belonging and adjustment have been identified (Ladd, Herald-Brown, \& Kochel, 2009; Juvonen \& Wentzel, 1996; Wentzel, 2005, 2009a; Wentzel et al., 2010).

Furthermore, teacher and peers may directly link students' achievement and motivation to direct or indirect reward and punishment. Neuroimaging studies have shown the involvement of the orbit frontal cortex in the processing of punishment and reward stimuli (O’Doherty, Kringelbach, Rolls, Hornak, \& Andrews, 2001; Elliott, Newman, Longe, \& Deakin, 2003), as well as the ventral striatum to be engaged in reward processing (e.g., Delgado, Nystrom, Fissell, Noll, \& Fiez, 2000). In order to understand adolescents' scholastic motivation in its entirety - brain development, brain activity as well as its interdependent relationship with students' environmental perception, behavior, and attitudes should be considered. One way to successfully bridge the gap between the involved disciplines in motivation research is method triangulation.

\section{Method Triangulative Procedure}

In the interdisciplinary study, the authors are following Treumann's method triangulative technique (see Figure 1): The methodological procedure (step 1) started in summer 2011 with a quantitative survey $(N=1,088$ students at Grades 7 and 8 in Brandenburg, Germany), investigating psychological aspects of socio-emotional factors, motivation, and achievement. Participants were asked to complete questionnaires assessing peer motivation, teacher motivation, academic achievement, and psychosocial variables. By using CLCA (confirmatory latent class analysis) with M-plus (L. K. Muthén \& B. O. Muthén, 1998-2010), it is confirmed four hypothesized self-perceived MTs (motivation types) (see Figure 2): (1) teacher-dependent MT; (2) peer-dependent MT; (3) teacher- and peer- dependent MT; and (4) teacher- and peer- independent MT. Membership for this four-class solution was as follows: 9.5\% teacher-dependent MT (50 girls, 57 boys), 36.5\% peer-dependent MT (233 girls, 161 boys), 27.8\% teacher- and peer- dependent MT (166 girls, 126 boys), and 
26.3\% teacher- and peer- independent MT (138 girls, 157 boys) (Raufelder, Jagenow, Drury, \& Hoferichter, 2012, in press).

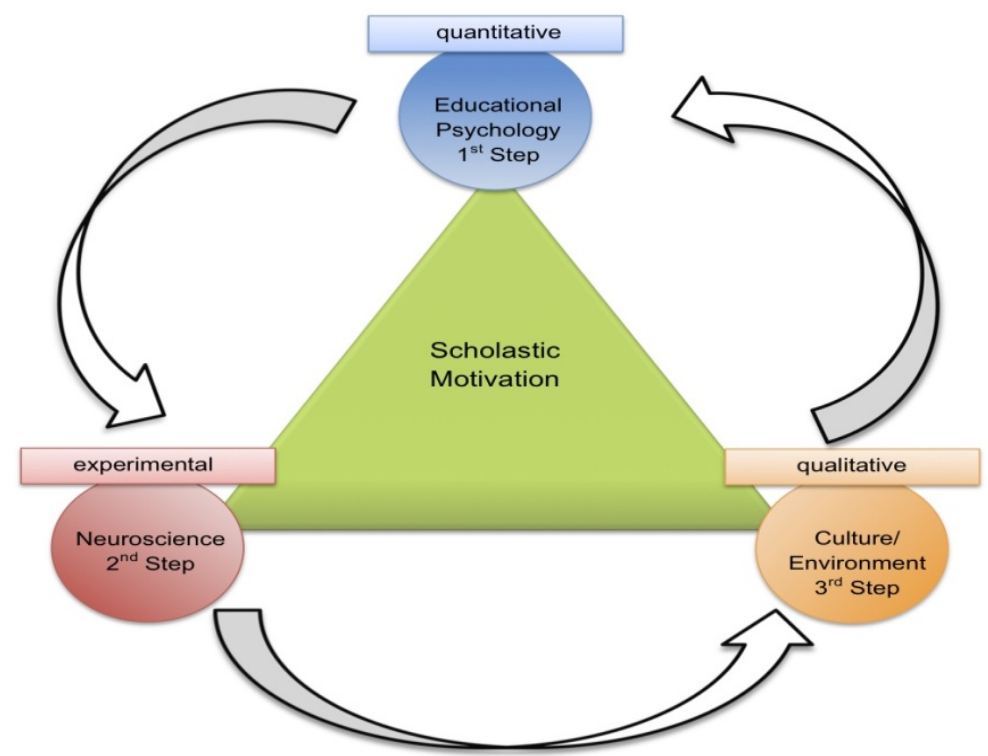

Figure 1. Method triangulative concept of the interdisciplinary study SELF in adolescents' scholastic motivation.

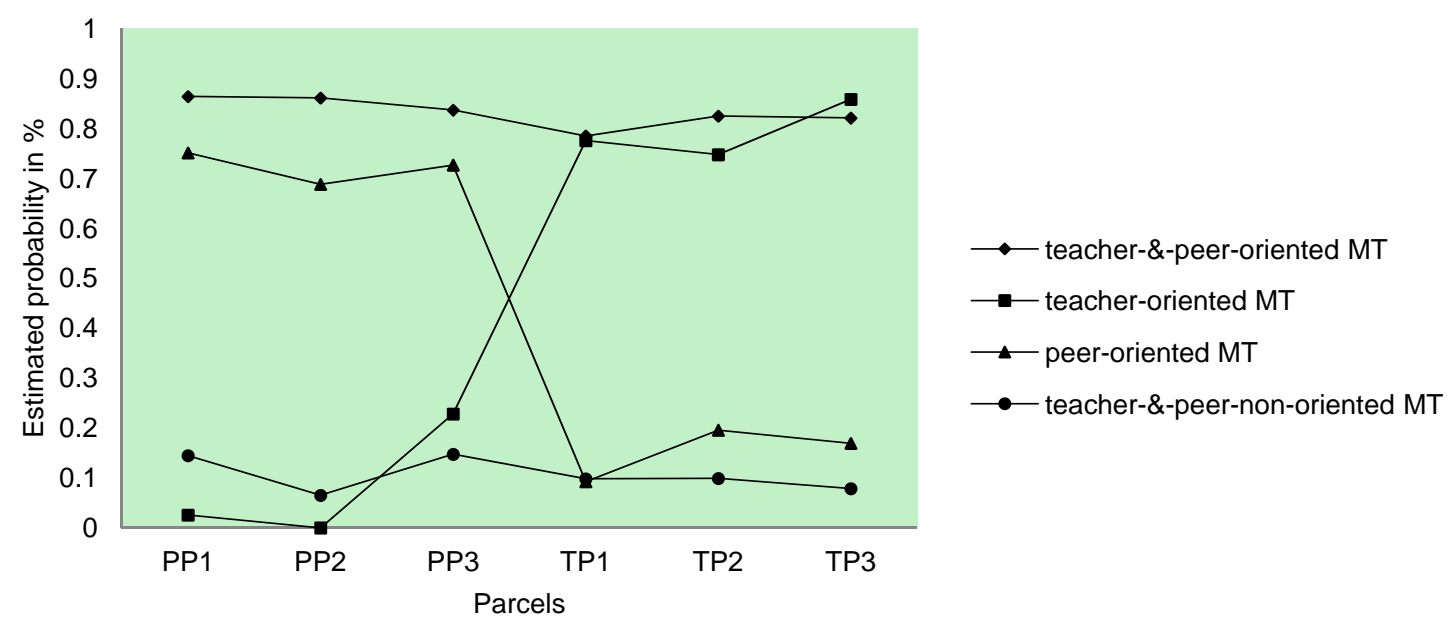

Notes. $X$-axis shows three "peers as motivators" parcels (1-3) and three "teacher as motivators" parcels (4-6) included in the model analyses; $Y$-axis shows probability of agreement with the clusters.

Figure 2. Confirmatory latent class analysis of social relationships and motivation.

In experimental studies (step 2), the variables of interest will be evaluated in terms of their effectiveness with maximal accuracy by using neuroscience procedures. Currently, we are testing for the differences in striatal activation between the four motivation types using a probabilistic learning task in an event-related fMRI study (Remijnse, Nielen, Uylings, \& Veltman, 2005). With this experimental design, a representative sample out of the 1,088 students $(N=48)$ with 12 individuals from each motivation type will be tested. This fMRI study has been designed and conducted in cooperation with the Charite Berlin (University Medical Center Berlin). In total, there will be three different paradigms: reversal learning, faces paradigm, and slot machine. 
The probabilistic reversal learning paradigm will be used to examine the flexible reward learning (Cools, Clark, Owen, \& Robbins, 2002). In addition, a "faces" paradigm will be used to examine the emotional ability to respond (limbic system). Specifically, old and adolescent faces will be shown in different moods (happy, anxious, angry, and neutral) to test for differences between the four identified motivation types. In the last paradigm, participants in the fMRI study will play a "slot machine" game to examine reward expectation and the associated motivation curve. In general, it is hypothesized that the four motivation types will differ in their neuronal reaction on reward and punishment. It is expected that the peer- and teacher- independent motivation type will show less neuronal responses on reward stimuli than the other three (more social oriented) motivation types.

Finally (step 3), the 48 students from the fMRI study will be interviewed to gain a more detailed description of the four different motivation types, the empirical reality of their relationships with teachers and peers, as well as the daily learning processes in school from the participants' point of view. Thirty minutes' semi-structured interview about peers and teachers as motivators, class climate, motivation, and learning strategies will be conducted. Using qualitative thematic analysis, several themes derived from patterns within the interviews will be identified to make more precise the motivation typology.

The whole method triangulative procedure will be repeated after two years to identify developmental changes characteristic of the motivation typology. The aim is to identify the typology as a constant or flexible construct (i.e., if a student was identified as a peer-dependent MT, will the student be a peer-dependent MT two years later, or is it possible to develop into another kind of motivation type?). The interdisciplinary focus which incorporates high quality objective and subjective measurements of scholastic motivation coupled with the longitudinal design will provide a truly unique knowledge base. By using method triangulative designs - including quantitative, qualitative, and experimental methods which also span disciplines (psychology and neuroscience), the authors minimize the weaknesses of each method and maximize their combination, while enriching and connecting the knowledge of each involved discipline. While quantitative research is focused on general descriptions to "explain" social reality, in form of general laws, qualitative and ethnographic research is more interested in "understanding" specific cases, to show how general laws work in particular cases (Becker, 1996). Quantitative research is often labeled as rational, logical, empirical, and positive science within the tradition of natural sciences. On the other hand, qualitative research is labeled as interpretative, understandable, and "weak". Seemingly so different, these research approaches are, in fact, grounded in the same leading idea: the description of social reality by investigating specific instances of social reality. Furthermore, the weaknesses of each method can be offset by linking different methodological approaches (Treumann, 2005). Quantitative and experimental studies are focused on majority (general laws), whereas qualitative studies are able to consider minorities (statistical outliers) while describing general laws in a deeper way (i.e., Geertz, 1973). According to this, the results of the neuroscience research group from the Charité (step 2) will help determine basic mechanisms of reward learning processes of adolescent students and will enrich the findings from the educational and psychological questionnaire study (step 1) as well as the qualitative interviews (step 3). Results from this study can help ensure that each student, whatever their motivation type is, will be fostered and supported within the school environment. Moreover, it is expected to identify basic principles of the interaction between motivation and socio-emotional aspects of adolescents by applying a behavioral, cognitive, as well as the biological (neuronal) approach. 


\section{Discussion}

With the current return to interdisciplinary studies, the question of how to combine diverse disciplines in a theoretical and empirical way becomes essential. To grasp and understand human phenomenon (such as motivation) in its complexity calls for interdisciplinary research that assumes an openness in the field to use different methods. The method triangulation, as presented in this article, is an attempt to bridge disciplines by interlinking different methods and therefore research traditions. Instead of using mixed methods independent from each other, the method triangulative technique interlocks each methodological step with the other. Therefore, the results can be understood as an additive process, in which the weakness of each method can be balanced through the strength of the other methods. The interdisciplinary contribution of the three different empirical methods (quantitative, experimental, and qualitative) provides an approach to understand human phenomena in their entirety.

\section{References}

Bailey, A., \& Hutter, I. (2008). Qualitative to quantitative: Linked trajectory of method triangulation in a study on HIV/AIDS in Goa, India. Aids Care, 20, 1119-1124. doi: 10.1080/09540120701842811

Birch, S. H., \& Ladd, G. W. (1996). Interpersonal relationships in the school environment and children's early school adjustment: The role of teachers and peers. In J. Juvonen, \& K. R. Wentzel (Eds.), Social motivation-Understanding children's school adjustment (pp. 199-225). Cambridge: University Press.

Blakemore, S. J., \& Frith, U. (2005). The learning brain: Lessons for education. Oxford: Blackwell.

Chambers, R. A., Taylor, J. R., \& Potenza, M. N. (2003). Developmental neurocircuitry of motivation in adolescence: A critical period of addiction vulnerability. American Journal of Psychiatry, 160, 1041-1052. doi: 10.1176/appi.ajp.160.6.1041

Chiao, J. Y. (2010). At the frontier of cultural neuroscience: Introduction to the special issue. Social Cognitive and Affective Neuroscience, 5, 109-110.

Cohen, L., Manion, L., \& Morrison, K. (2000). Research methods in education. London: Routledge/Falmer.

Coie, J. D., Lochman, J. E., Terry, R., \& Hyman, C. (1992). Predicting early adolescent disorder from childhood aggression and peer rejection. Journal of Consulting and Clinical Psychology, 60, 783-792. doi: 10.1037//0022-006X.60.5.783

Cools, R., Clark, L., Owen, A. M., \& Robbins, T. W. (2002). Defining the neural mechanisms of probabilistic reversal learning using event-related functional magnetic resonance imaging. Journal of Neuroscience, 22, 4563-4567.

Deci, E. L., \& Ryan, R. M. (1985). Intrinsic motivation and self-determination in human behavior. New York, N. Y.: Plenum.

Deci, E. L., \& Ryan, R. M. (Eds.). (2000). Handbook of self-determination research. Rochester, N. Y.: University of Rochester Press.

Delgado, M. R., Nystrom, L. E., Fissell, C., Noll, D. C., \& Fiez, J. A. (2000). Tracking the hemodynamic responses to reward and punishment in the striatum. Journal of Neurophysiology, 84, 3072-3077.

DeRosier, M. E., Kupersmidt, J. B., \& Patterson, C. J. (1994). Children's academic and behavioral adjustment as a function of the chronicity and proximity of peer rejection. Child Development, 65, 1799-1813.

Dorman, C., \& Gaudiano, P. (1998). Motivation. In M. A. Arbib (Ed.), The handbook of brain theory and neural networks (pp. 591-594). Cambridge, Mass: MIT Press.

Eccles, J. S., \& Midgley, C. (1990). Changes in academic motivation and self-perceptions during early adolescence. In R. Montemayor, G. R. Adams, \& T. P. Gullotta (Eds.), Advances in adolescent development: From childhood to adolescence (pp. 134-155). Newbury Park, C. A.: Sage.

Elliott, R., Newman, J. L., Longe, O. A., \& Deakin, J. F. (2003). Differential response patterns in the striatum and orbito frontal cortex to financial reward in humans: A parametric functional magnetic resonance imaging study. Journal of Neuroscience, 23, 303-307.

Erikson, E. H. (1959). Identity and the life cycle. New York, N. Y.: International University Press.

Erzberger, C., \& Prein, G. (1997). Triangulation: Validity and empirically-based hypothesis construction. Quality and Quantity, 31, 141-154.

Flanagan, K. S., Erath, S. A., \& Bierman, K. L. (2008). Unique associations between peer relations and social anxiety in early adolescents. Journal of Clinical Child and Adolescent Psychology, 37, 759-769. doi: 10.10807/15374410802359700 
Geertz, C. (1973). The interpretation of cultures. London: Hutchinson \& Co..

Goleman, D. (2004). Foreword. In J. E. Zins, R. P. Weissberg, M. C. Wang, \& H. C. Walberg (Eds.), Building academic success on social and emotional learning (pp. 7-8). New York, N. Y.: Teachers College Press.

Greenough, W. T., Black, J. E., \& Wallace, C. S. (1987). Experience and brain development. Child Development, 58, 539-559. doi: $10.2307 / 1130197$

Harter, S. (1996). Teacher and classmate influences on scholastic motivation, self-esteem, and level of voice in adolescents. In J. Juvonen, \& K. Wentzel (Eds.), Social motivation-Understanding children's school adjustment (pp. 11-42). Cambridge: University Press. doi: 10.1207/s15326985ep3401_5

Hodis, F. A., Meyer, L. H., McClure, J., Weir, K. F., \& Walkey, F. H. (2011). A longitudinal investigation of motivation and secondary school achievement using growing mixture modeling. Journal of Educational Psychology, 103, 312-323. doi: $10.1037 / \mathrm{a} 0022547$

Juvonen, J., \& Wentzel, K. R. (1996). Social motivation: Understanding children's school adjustment. New York, N. Y.: Cambridge University Press.

Kindermann, T. A. (1993). Natural peer groups as contexts for individual development: The case of children's motivation in school. Developmental Psychology, 29, 970-977. doi: 10.1037/0012-1649.29.6.970

Ladd, G. W., Herald-Brown, S. L., \& Kochel, K. P. (2009). Peers and motivation. In K. R. Wentzel, \& A. Wigfield (Eds.), Handbook of motivation at school (pp. 323-348). New York, N. Y.: Routledge.

LeBlanc, H. P. III. (1995). Syncretism of qualitative and quantitative research paradigms: The case for methodological triangulation. Paper presented at the Family Communication Division Pre-convention Conference of the Eighty-First Annual Meeting of the Speech Communication Association, San Antonio, T. X..

Leo, E. L., \& Galloway, D. (1996). Evaluating research on motivation: Generating more heat than light? Evaluation \& Research in Education, 10, 35-48.

McClelland, D. C., Atkinson, J. W., Clark, R. A., \& Lowell, E. L. (Eds.). (1953). The achievement motive. New York, N. Y.: Appleton-Century-Crofts.

McGarth, J. E. P., Joanne, M., \& Kulka, R. (1982). Judgment calls in research. Beverly Hills, C. A.: Sage.

Miles, M., \& Huberman, A. (1994). Qualitative data analysis: An expanded sourcebook. Thousand Oaks, C. A.: Sage Publications.

Moore, S. M., \& Rosenthal, D. A. (1992). Venturesomeness, impulsiveness, and risky behavior among older adolescents. Perceptual \& Motor Skills, 76, 98.

Moran-Ellis, J., Alexander, V. D., Cronin, A., Dickinson, M., Fielding, J., Sleney, J., \& Thomas, H. (2006). Triangulation and integration: Processes, claims and implications. Qualitative Research, 6, 45-59.

Muthén, L. K., \& Muthén, B. O. (1998-2010). Mplus user's guide (6th ed.). Los Angeles, C. A.: Muthén \& Muthén.

Nickel, H. (1981). Die Transaktionalität der Lehrer-Schüler-Beziehung und ihre Bedeutung für die Unterrichtspraxis. In A. Weber (Ed.), Lehrerhandeln und unterrichtmethode. München: Wilhelm Fink.

O'Doherty, J., Kringelbach, M. L., Rolls, E. T., Hornak, J., \& Andrews, C. (2001). Abstract reward and punishment representations in the human orbit frontal cortex. Nature Neuroscience, 4, 95-102.

Ollendick, T. H., Weist, M. D., Borden, M. G., \& Greene, R. W. (1992). Sociometric status and academic, behavioral, and psychological adjustment: A five-year longitudinal study. Journal of Consulting and Clinical Psychology, 60, 80-87. doi: 10.1037/0022-006X.60.1.80

Popp, U. (2002). Gender socialization and school violence: Gender specific expressions and conflicted interactions of students. Weinheim: Juventa.

Raufelder, D., \& Mohr, S. (2011). The meaning of socio-emotional factors in school context considering neuro-scientific aspects. In A. Ittel, H. Merkens, L. Stecher, \& J. Zinnecker (Eds.), Yearbookof youth reserach (pp.74-96). Wiesbaden: V. S. Verlag. doi: 10.1007/978-3-531-93116-6_1

Raufelder, D., Jagenow, D., Drury, K., \& Hoferichter, F. (2012). Social relationships and motivation in secondary schools: Four different motivation types. In Learning and individual differences (in press). doi: 10.1016/j.lindif.2012.12.002

Remijnse, P. L., Nielen, M. M., Uylings, H. B., \& Veltman, D. J. (2005). Neural correlates of a reversal learning task with an affectively neutral baseline: An event-related fMRI study. Neuroimage, 26, 609-618.

Rubin, K. H., Bukowski, W. M., \& Parker, J. (2006). Peer interactions, relationships, and groups. In N. Eisenberg (Ed.), Handbook of child psychology: Social, emotional, and personality development (6th ed., pp. 571-645). New York, N. Y.: Wiley. doi: 10.1002/9780470147658 
Rubin, K. H., Bukowski, W. M., \& Laursen, B. (Eds.). (2009). Handbook of peer interactions, relationships, and groups. New York, N. Y.: Guilford Press.

Sharp, H. (1943). Photogrammetry (3rd ed.). New York, N. Y.: John Wiley.

Stipek, D. J. (1996). Motivation and instruction. In D. C. Berliner, \& R. C. Calfee (Eds.), Handbook of educational psychology (pp. 85-113). New York, N. Y.: Macmillan.

Treumann, K. P. (2005). Cluster-analytic selection of prototypical cases for qualitative research: The triangulative combination of quantitative and qualitative methods. In S. Schilling, J. Sparfeldt, \& C. Pruisken (Eds.), Current aspects of educational-psychological research (pp. 41-70). Münster: Waxmann.

Waugh, R. F. (2002). Creating a scale to measure motivation to achieve academically: Linking attitudes and behaviours using Rasch measurement. British Journal of Educational Psychology, 72, 65-86.

Weiner, B. (1990). History of motivational research in education. Journal of Educational Psychology, 82, 616-622.

Wentzel, K. R. (1996). Social goals and social relationships as motivators of school adjustment. In J. Juvonen, \& K. Wentzel (Eds.), Social motivation-Understanding children's school adjustment (pp. 226-247). Cambridge: University Press. doi: 10.1207/s15326985ep3401_5

Wentzel, K. R. (1998). Social relationships and motivation in middle school: The role of parents, teachers and peers. Journal of Educational Psychology, 90, 202-209. doi: 10.1037/0022-0663.90.2.202

Wentzel, K. R. (2003). School adjustment. In W. Reynolds, \& G. Miller (Eds.), Handbook of psychology: Educational psychology (Vol. 7, pp. 235-258). New York, N. Y.: Wiley.

Wentzel, K. R. (2005). Peer relationships, motivation, and academic performance at school. In A. J. Elliot, \& C. S. Dweck (Eds.), Handbook of competence and motivation (pp. 279-296). New York, N. Y.: Guilford.

Wentzel, K. R. (2009a). Peer relationships and motivation at school. In K. Rubin, W. M. Bukowski, \& B. Laursen (Eds.), Handbook of peer interactions, relationships, and groups (pp. 531-547). New York, N. Y.: Guilford.

Wentzel, K. R. (2009b). Students' relationships with teachers as motivational contexts. In K. Wentzel, \& A. Wigfield (Eds.), Handbook of motivation at school (pp. 301-322). Mahwah, N. J.: LEA.

Wentzel, K. R., Battle, A., Russell, S. L., \& Looney, L. B. (2010). Social supports from teachers and peers as predictors of academic and social motivation. Contemporary Educational Psychology, 35, 193-202. doi: 10.1016/j.cedpsych.2010.03.002

Wigfield, A., \& Eccles, J. S. (Eds.). (2001). Development of achievement motivation. San Diego, C. A.: Academic Press.

Wigfield, A., Eccles, J. S., \& Rodriguez, D. (1998). The development of children's motivation in school contexts. In P. D. Pearson, \& A. Iran-Nejad (Eds.), Review of research in education (Vol. 23, pp. 73-118). Washington, D. C.: American Educational Research Association. doi: 10.3102/0091732X023001073

Yates, T. (1996). Theories of cognitive development. In M. Lewis (Ed.), Child and adolescent psychiatry (pp. 134-155). Baltimore, M. D.: Williams \& Wilkins. 